Www.jmscr.igmpublication.org

Impact Factor (SJIF): 6.379

Index Copernicus Value: 79.54

ISSN (e)-2347-176x ISSN (p) 2455-0450

crossrefDOI: https://dx.doi.org/10.18535/jmscr/v6i12.126

Journal Of Medical Science And Clinical Research

\title{
A study to evaluate the effect of Dexmedetomidine and Ketamine as adjuvant to epidural bupivacaine for postoperative analgesia in gynaecological surgeries
}

\author{
Authors \\ Dr Manoranjan Mahapatra ${ }^{1}$, Dr Aratiprava Sahu ${ }^{2 *}$ \\ ${ }^{1}$ Asst. Prof., Dept of Gynaecologic Oncology, AHRCC, Cuttack, Odisha, India \\ ${ }^{2}$ Asst. Prof., Dept of Anaesthesiology, AHRCC, Cuttack, Odisha, India \\ *Corresponding Author \\ Dr Aratiprava Sahu \\ Email:drkitusraban@gmail.com
}

\begin{abstract}
Aim: So many adjuvants have been used with bupivacaine in epidural anaesthesia but none has been found ideal. We have conducted this study to evaluate the effect of epidural dexmedetomidine and ketamine when added to bupivacaine.

Methods: Fifty female patients who underwent hysterectomies under epidural anesthesia were included in this study. They were randomly allocated in to two groups of 25 each. Group BK received epidural bupivacaine $0.5 \%(15 \mathrm{ml})+0.5 \mathrm{mg} / \mathrm{kg}$ of ketamine $(1 \mathrm{ml})$ and group BD received epidural bupivacaine $0.5 \%$ $(15 \mathrm{ml})+0.5 \mu \mathrm{g} / \mathrm{kg}$ of dexmedetomidine $(1 \mathrm{ml})$. Following epidural administration, onset and duration of sensory and motor blockade, maximum dermatomal level achieved, duration of analgesia and incidence of side effects were recorded.

Results: Onset of sensory and motor block was earlier in group BD compared to group BK which was statistically significant. Block regression was significantly delayed with the addition of epidural dexmedetomidine (Group BD) as compared to group BK. The duration of analgesia was also significantly prolonged in group $B D$ as compared to group BK. There were no significant difference either in haemodynamic parameters or in the incidence of side effects in both the groups.

Conclusion: Dexmedetomidine when added to epidural bupivacaine produces significantly longer sensory and motor blockade along with prolonged postoperative analgesia when compared to epidural ketamine. Dexmedetomidine provided haemodynamic stability without any significant side effects.

Keywords: Dexmedetomidine, bupivacaine, epidural, gynaecological, ketamine.
\end{abstract}

\section{Introduction}

Epidural anaesthesia is the most popular regional anaesthesia techniques used for ggynecological surgeries. The advantages of epidural anaesthesia being that;

It provides effective surgical anesthesia and can meet the extended duration of surgical needs.
Provides prolonged post-operative analgesia and reduces the incidence of hemodynamic changes as a result of the symapathetic blockade as it produces segmental anaesthesia, unlike subarachnoid block/anaesthesia.

There is no incidence of PDPH (post dural puncture headache) as the dura is not 
pierced.Epidural anaesthesia reduces the surgical stress by blocking the nociceptive impulses from the operative site, reduces blood loss, improve respiratory and bowel function and decreased incidence of deep vein thrombosis. ${ }^{1}$

However, due to large volumes of local anaesthetic drugs used for achieving the desired effect, epidural anaesthesia may be associated with haemodynamic fluctuations leading to deleterious consequences. ${ }^{2}$

To overcome these problems, there is an ongoing effort to find a better adjuvant in regional anaesthesia. Sedation, stable haemodynamics and ability to provide smooth and prolonged post operative analgesia are the main desirable qualities of an adjuvant in neuraxial anaesthesia. ${ }^{3}$ Various additives have been used for extending the duration of central neuraxial block to prolong the effect of local anaesthetic agents. These include drugs like Opioids, Ketamine, Midazolam, Neostigmine and $\alpha_{2}$ adrenergic agonists. ${ }^{4} \alpha_{2}$ adrenergic agonists have both analgesic and sedative properties when used as an adjuvant in regional anaesthesia. Dexmedetomidine is a highly selective $\alpha_{2}$ adrenergic agonist with anxiolytic and perioperative sympatholytic anti hypertensive properties. It also enhances post operative analgesia. ${ }^{4}$

N-methyl-D-Aspartate (NMDA) receptor was found to play a significant role in injury induced spinal hypersensitivity. Also, sensitisation of the central nervous system may account for significant post operative pain.

Blockade of NMDA receptors before and during injury may prevent or reduce development of central sensitisation. NMDA receptor antagonists like Ketamine can potentiate the effects of other analgesics like morphine, local anaesthetics and non steroidal anti-inflammatory agents. ${ }^{5}$

As an NMDA receptor antagonist, Ketamine may produce additive or synergistic effect with intra operative and post operative pain relief.

Hence we have compared Bupivacaine with Dexmedetomidine and Bupivacaine with
Ketamine in ggynecological surgeries in epidural anaesthesia.

\section{Methods}

After obtaining the approval from the hospital ethical committee and written informed consent from the patient, the study was conducted on 50 patients belonging to ASA Grade I and II, scheduled for ggynecological surgeries during the period October 2015 - November 2016.

The study population was randomly divided using computer-generated randomization into 2 groups with 25 patients in each group.

- Group BK (Bupivacaine-Ketamine): Group BK received epidural bupivacaine $0.5 \%$ $(15 \mathrm{ml})+0.5 \mathrm{mg} / \mathrm{kg}$ of ketamine (diluted to1ml)

- Group BD (BupivacaineDexmedetomidine): Group BD epidural bupivacaine $0.5 \%(15 \mathrm{ml})+0.5 \mu \mathrm{g} / \mathrm{kg}$ of dexmedetomidine $(1 \mathrm{ml})$

\section{Inclusion Criteria}

- ASA Grade I or II

- Adult patients between 38 years to 65 years of age

- Weight- 40-70 Kg

- Height :140-180 centimeters

\section{Exclusion Criteria}

- Patient's refusal for regional anesthesia

- Emergency surgeries

- Obese patients with BMI(Body Mass Index) $>30$

- bleeding disorder, coagulopathy

- uncontrolled hypertension/Diabetes mellitus

- local infection

Pre anesthetic check up was done one day prior to the surgery. Patients were evaluated for any systemic diseases and laboratory investigations recorded. The standard investigations were performed in all patients. The epidural procedure was explained to the patients and consent for the same was obtained. Preparation of patients included period of overnight fasting. The patients were premedicated with Tablet Alprazolam 0.5 
$\mathrm{mg}$ and Tablet Ranitidine $150 \mathrm{mg}$ orally at bedtime on the night before surgery. The patient's Pulse rate and Blood Pressure were recorded. A peripheral I.V line was secured with an $18 \mathrm{G}$ (gauge) cannula. The patients were preloaded with $500 \mathrm{ml}$ of Ringer's Lactate 30 minutes prior to the epidural procedure. Multipara monitor were connected which recorded:

* Heart rate

* Non invasive measurement of Systolic Blood Pressure(SBP), Diastolic

Blood Pressure (DBP) and Mean Arterial Pressure (MAP)

\section{* Continuous ECG \\ * $\mathrm{SpO}_{2}$}

With the patients in sitting position, under all available aseptic precautions, the epidural space was identified by the loss of resistance technique using $18 \mathrm{G}$ Tuohy needle via midline approach at either $\mathrm{L}_{2-3}$ or $\mathrm{L}_{3-4}$ interspinous space. An epidural catheter was threaded and fixed at $3 \mathrm{~cm}$ inside epidural space. A test dose of $3 \mathrm{ml}$ of $2 \%$ Lignocaine with 1:200000 Adrenaline was injected through the epidural catheter after aspiration. After ruling out the intrathecal and intravascular placement of the tip of the catheter, the drug under study was injected in increments of $5 \mathrm{ml}$. The patient was then turned to supine position.

Assessment of sensory and motor blockade was done at the end of each minute with the patient in supine position, after completion of injection of 16 $\mathrm{ml}$ of the study drug, which was taken as the starting time. The onset time for sensory and motor blockade, the maximum level of sensory block, intensity of motor block and sedation score was recorded.

The sensory blockade was assessed by pinprick method using a short bevel $22 \mathrm{G}$ needle and tested in mid-clavicular line on the chest, trunk and lower limbs on either side. Motor blockade was assessed using modified Bromage scale. ${ }^{6}$

Modified Bromage scale for motor blockade:

$$
\begin{aligned}
& * 0=\text { No block } \\
& * 1=\text { inability to raise extended leg }
\end{aligned}
$$

* 2=inability to flex knee

* 3=inability to flex ankle and foot, able to move toes

* 4=inability to flex ankle and foot, not able to move toes

Measurement of Blood Pressure, Heart Rate and $\mathrm{O}_{2}$ saturation was recorded every 5 minutes till the end of first hour and then every 15 minutes till the end of surgery.

After the surgery, patients were referred to the recovery room where they remained till the complete recovery from sensory and motor blockade.

Postoperatively, the vital parameters was recorded every 15 minutes; also the duration of sensory blockade and motor blockade or any adverse events were noted. The time of onset of sensory blockade was taken from time of injection of the drug under study into the epidural space to loss of pin prick sensation. Time of onset of T10 sensory block and peak sensory block was noted using pin prick method. Onset of Motor blockade was taken as the time from the completion of the injection of the drug under study till the patient developed modified Bromage scale Grade 1.The highest level of sensory block was noted from time of injection of drug to loss of pinprick sensation at highest dermatomal level. The maximum motor blockade was noted from time of injection of the drug to maximum degree of motor block. 7,8 Grading of sedation was evaluated by Five point scale: ${ }^{9}$

- $1=$ Alert and wide awake

- $2=$ Arousable to verbal command

- $3=$ Arousable with gentle tactile stimulation

- $4=$ arousable with vigorous shaking

- $5=$ unarousable

Sedation score was recorded just before initiation of surgery and every 5 minutes till 1 hour and then every 15 minutes throughout the surgical procedure.

Duration of sensory blockade was recorded as the interval from the time of onset of sensory blockade till the patient complains of pain at $T_{10}$ 
dermatome. Duration of motor block was recorded from onset time to time when the patient was able to lift the extended leg. During the surgical procedure, adverse events like anxiety, nausea, vomiting, pruritus and shivering were noted. Nausea and vomiting was treated with Inj Ondansetron 4mg IV.

Statistical Analysis: At the end of the study, all the data was compiled systematically and analyzed using student's t-test, and Pearson chisquare test. All the values were expressed as mean \pm standard deviation. Statistical Package for Social Sciences Version 21.0 for Windows was used to compare the variables between two groups. Value of $\mathrm{P}<0.05$ considered significant and $\mathrm{P}<0.001$ as highly significant.

\section{Results}

Table No -1 Patient's characteristics

\begin{tabular}{|l|c|c|c|}
\hline Variables & Group BK & Group BD & P value \\
\hline Age $(\mathrm{yrs}$.) & $38.70 \pm 12.98$ & $40.26 \pm 10.15$ & 0.547 \\
\hline Height $(\mathrm{cm})$ & $177.16 \pm 13.32$ & $159 \pm 11.4$ & 0.82 \\
\hline Weight $(\mathrm{kg})$ & $58.92 \pm 5.91$ & $61.52 \pm 6.33$ & 0.360 \\
\hline $\begin{array}{l}\text { ASA } \\
\begin{array}{l}\text { Physical } \\
\text { status(I/II) }\end{array}\end{array}$ & $15 / 10$ & $14 / 11$ & 0.728 \\
\hline
\end{tabular}

The age, height, weight and ASA status was comparable between the two groups.(Table1)

Fig-1

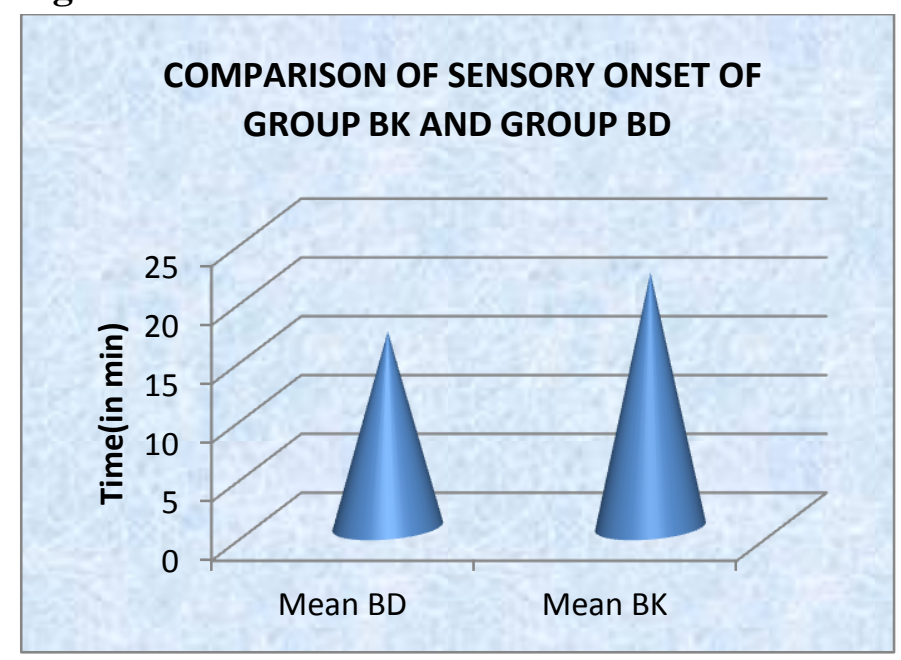

Onset of sensory blockade at T10 level was faster in group BD $(11.80 \pm 2.42 \mathrm{~min})$ as compared to group BK (16.86 $\pm 2.44 \mathrm{~min})$ and the difference was statistically significant. The maximal dermatomal level of analgesia and maximum motor blockade were comparable in both groups. (fig1,2)

Fig-2

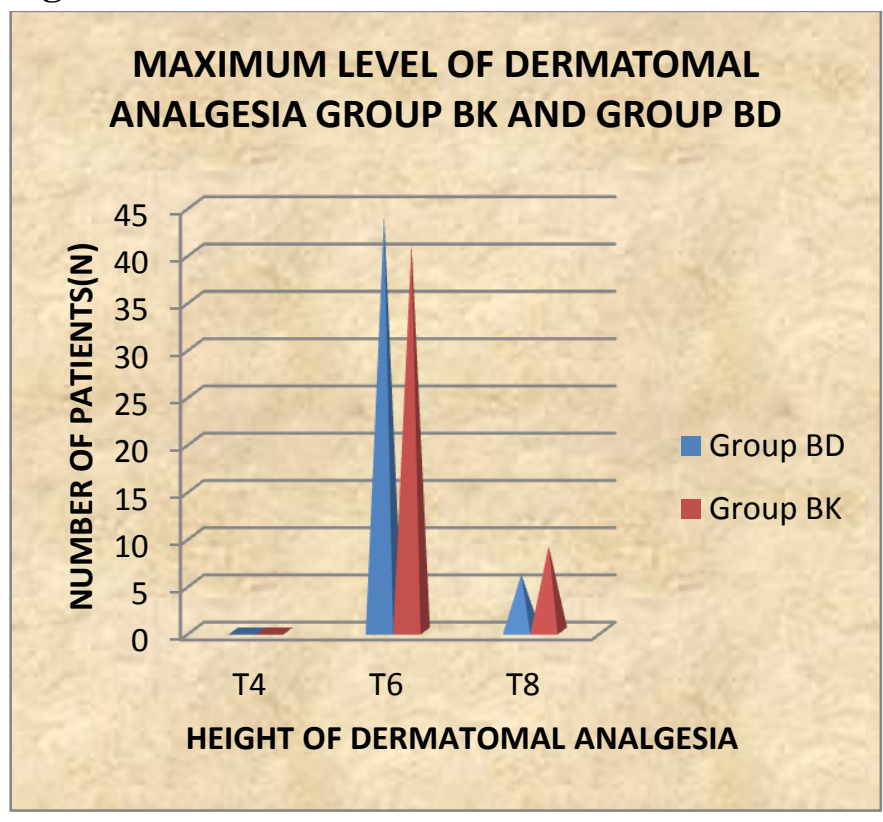

Fig-3

\section{COMPARISON OF SENSORY DURATION OF GROUP BK AND GROUP BD}

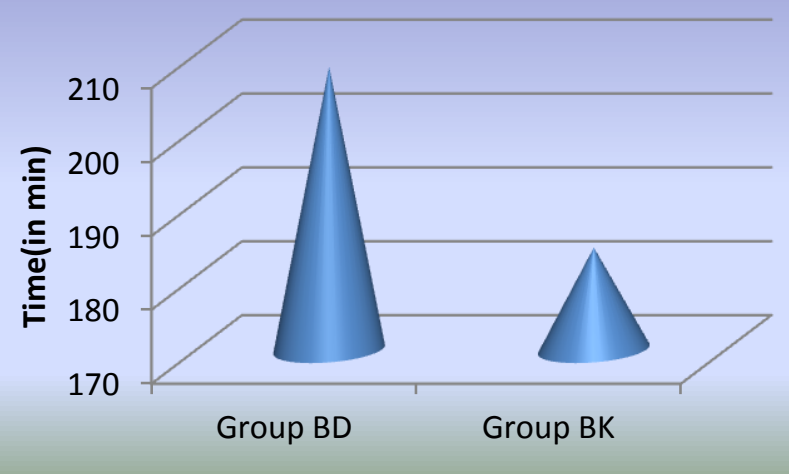

Mean duration of analgesia in group BD was of longer (208.3 $\pm 15.03 \mathrm{~min}$ ) as compared to group BK $(183.8 \pm 14.3 \mathrm{~min})$ and the difference was statistically significant. Mean duration for motor blockade was shorter in group BK $(169.2 \pm 13.86$ min) as compared to group BD $(191.1 \pm 15.46$ min), which was significant statistically.(fig 3,4$)$ 
Fig-4

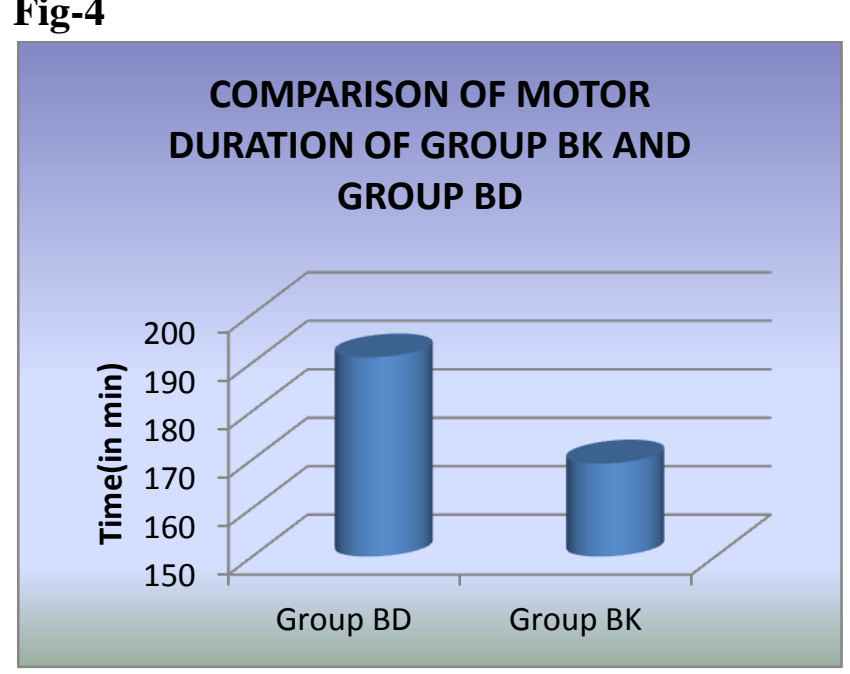

Sedation score intraoperatively was higher in group BD compared to group BK from 5 mins up to $120 \mathrm{~min}$ and the difference was statistically significant. (fig5)

\section{Fig-5}

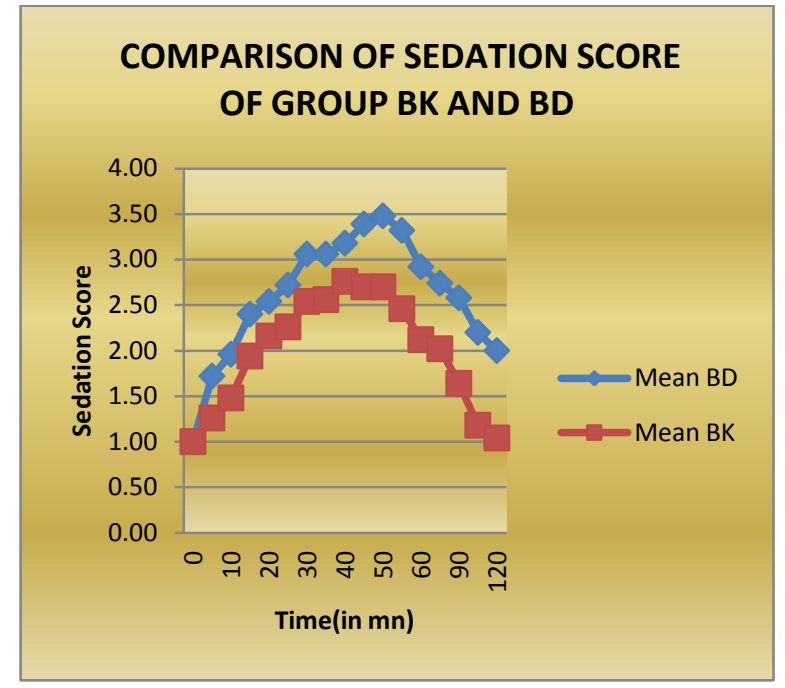

Incidence of side effects like dry mouth, nausea, shivering, neurological sequel, and bradycardia were comparable in both groups, $\mathrm{BK}$ and $\mathrm{BD}$. (table2)

Table No-2 Comparison of adverse effects

\begin{tabular}{|l|c|c|c|}
\hline Side Effects & Group BK & Group BD & P value \\
\hline Shivering & 2 & 2 & $>0.001$ \\
\hline Hypotension & 1 & 2 & $>0.001$ \\
\hline Nausea & 2 & 2 & $>0.001$ \\
\hline Vomitting & 0 & 0 & $>0.001$ \\
\hline Bradycardia & 1 & 2 & $>0.001$ \\
\hline $\begin{array}{l}\text { Neurological } \\
\text { Sequel }\end{array}$ & 0 & 0 & $>0.001$ \\
\hline
\end{tabular}

\section{Discussion}

Over the years many adjuvants have been used along with local anaesthetics in neuraxial anaesthesia. The use of opioids as adjuvant are associated with quite a few side effects such as respiratory depression, nausea, vomiting, urinary retention and pruritus. ${ }^{10}$

So various options including $\alpha_{2}$ agonist are being studied as an alternative adjuvant in neuraxial anaesthesia. The pharmacologic properties of $\alpha_{2}$ agonists have been extensively studied and have been employed clinically to achieve the desired effects as adjuvant to local anaesthetics. Similarly, Ketamine (NMDA antagonist) has also been tried. Epidural administration of these drugs are associated with sedation, analgesia, anxiolysis and sympatholysis. ${ }^{11}$

Introduction of Dexmedetomidine has widened the scope of $\alpha_{2}$ agonists in regional anaesthesia. Ketamine has a NMDA receptor antagonistic activity and prevents central sensitisation. The faster onset of action when given along with local anaesthetics, rapid establishment of both sensory and motor blockade, prolonged duration of analgesia into the post-operative period, makes these agents very effective adjuvants in regional anaesthesia.

The present study was undertaken to compare onset and establishment of sensory and motor blockade, sedation and haemodynamic profiles of Dexmedetomidine ( $\alpha_{2}$ agonist) with Ketamine as an adjuvant to Bupivacaine.

Shaikh et al ${ }^{12}$ carried out study to evaluate the efficacy of epidural dexmedetomidine and clonidine as an adjuvant to bupivacaine with special emphasis on their quality of analgesia, sedation and the ability to provide the smooth intra-operative and postoperative course. They concluded that Dexmedetomidine is a superior neuraxial adjuvant to bupivacaine when compared to clonidine for early onset of analgesia, and prolonged postoperative analgesia.Gupta et $\mathrm{al}^{13}$ did a study aimed to compare the hemodynamic, sedative, and analgesia potentiating effects of dexmedetomidine versus fentanyl with epidural 
$0.5 \%$ levobupivacaine for vaginal hysterectomy. They observed that Dexmedetomidine was better than fentanyl as an epidural adjuvant for providing early onset of sensory analgesia, adequate sedation with no respiratory depression and prolonged postoperative analgesia.

Waleed $\mathrm{S}$ et $\mathrm{al}^{14}$ carried out a study to compare the analgesic efficacy and safety of ketamine and magnesium sulfate in combination with bupivacaine for caudal blockade in pediatric patients after inguinoscrotal operations. It was observed that caudal administration of ketamin is efficient and safe for pediatric inguinoscrotal operations with longer postoperative analgesia than magnesium sulfate. Alireza et $\mathrm{al}^{15}$ carried out a study to compare the addition of neostigmine and ketamine to bupivacaine $0.25 \%$ for epidural analgesia increasing duration of postoperative analgesia. Both Neostigmine and ketamine with bupivacaine $0.25 \%$ for epidural anesthesia increased the duration of analgesia during the postoperative period and reduced analgesic consumption that about ketamine was more than neostigmine. Sonawane et $\mathrm{al}^{16}$ concluded that Dexmedetomidine is a superior neuraxial adjuvant to bupivacaine when compared to ketamine for early onset of analgesia, superior intra-operative analgesia, stable cardio-respiratory parameters, prolonged postoperative analgesia and providing patient comfort.

\section{Conclusion}

Our study concluded that epidural dexmedetomidine compared to ketamine when added to bupivacaine, provided prolonged sensory and motor blockade, better postoperative analgesia and excellent haemodynamic stability with minimal side effects

\section{References}

1. Bajwa SJ, Bajwa SK, Kaur, J Singh G, Arora V, Gupta S, et al. Dexmedetomidine and clonidine in epidural anaesthesia: A comparative evaluation. Indian J Anaesth 2011;55:116-21.
2. Esmaoglu A, Mizrak A, Akin A, Turk Y and Boyaci A. Addition of dexmedetomidine to lidocaine for intravenous regional anaesthesia. Eur $\mathrm{J}$ Anaesthesiol. 2005; 22:447-51.

3. Herd DW, Anderson BJ,Holford NH: Modeling the norketamine metabolite in children and the implications for analgesia. Paediatr Anaesth 2007;17:831-840

4. Clements JA,Nimmo WS: Pharmacokinetics and analgesic effect of ketamine in man.Br J Anaesth 1981:53:27-30

5. Grant IS,Nimmo WS,Clements JA: Pharmacokinetics and analgesic effect if i.m and oral ketamine .Br J Anaesth 1981;53:805-810

6. GeisslingerG,Hering W,Thomann $P$ et al: Pharmacokinetics and pharmacodynamics of ketamine enantiomers in surgical patients using a stereoselective analytical method.Br J Anaesth 1993:;70:666-671

7. Ohtani M,Kikuchi H,Kitahata LM,et al: Effects of ketamine on nociceptive cells in the medial medullary reticular formation of the cat.Anesthesiology 1979;51:414417

8. EI-Hennawy, A. M., Abd-Elwahab, A. M., Abd-Elmaksoud, A. M., EI-Ozairy, H. S., \& Boulis, S. R. (2009). Addition of Clonidine or Dexmedetomidine to Bupivacaine prolongs caudal analgesia in children. British journal of anaesthesia, 103(2),268-274.

9. Elhakim, M., Abdelhamid, D., Abdelfattach, H., Magdy, H., Elsayed, A., \& Eishafei, M. (2010). Effect of epidural Dexmedetomidine on intraoperative awareness and post-operative pain after one-long ventilation.Acta anaesthesiologica Scandinavica, 54(6), 703-709.

10. Anand VG, Kannan M, Thavamani A, Bridgit MJ. Effects of dexmedetomidine added to caudal ropivacaine in paediatric lower abdominal surgeries. Indian $\mathbf{J}$ Anaesth 2011;55:340-6 
11. Slobodan Mihaljevic, Ljiljana Mihaljevic, Marko Cacic et al ; Sympathetic activity of $\mathrm{S}$-(+)-ketamine low doses in the epidural space;Rev. Bras. Anestesiol. vol.64 no.4 Campinas July/Aug. 2014;p 227-335

12. Shaikh SI, Mahesh SB. The efficacy and safety of epidural dexmedetomidine and clonidine with bupivacaine in patients undergoing lower limb orthopedic surgeries. J Anaesthesiol Clin Pharmacol 2016;32:203-9

13. Gupta K, Bhawna Rastogi, Prashant K. Gupta, Manish Jain, Suneeta Gupta, Deepti Mangla; Epidural $0.5 \%$ levobupivacaine with dexmedetomidine versus fentanyl for vaginal hysterectomy: A prospective study; Indian Journal of Pain ; September-December 2014 ; Vol 28 ;Issue 3 14;p 149-54

14. Walleed S, Ibrahim AS, Mostafa MG, Kurkar A, Elderwy AA. Ketamine versus magnesium sulfate with caudal bupivacaine block in pediatric inguinoscrotal surgery: A prospective randomized observer-blinded study. Urol Ann. 2015;7(3):325-9.

15. Alireza Kamali, Abbas Zareei, Esmaeil Moshiri, Fariba Farokhi; Comparing the Effect of Adding Ketamine and Neostigmine to Bupivacaine $0.25 \%$ for Epidural Analgesia among Patients Candidated for Elective Femoral Fracture Surgery; International Journal of Medical Research \& Health Sciences, 2016, 5, 11:63-67.

16. Sonawane NB, Balavenkatasubramanian J, Gurumoorthi P, Jadhav PA. Quality of post-operative analgesia after epidural dexmedetomidine and ketamine: A comparative pilot study. Indian J Anaesth. 2016;60(10):766-768. 